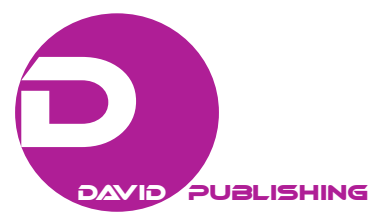

\title{
Ephemeral Art and Interactive Art: The Quest for Preservation and Dissemination
}

\author{
Suzete Venturelli, Antenor Ferreira Corrêa \\ University of Brasília, Brasília, Brazil
}

\begin{abstract}
In this text, we seek to present and analyze artistic works that were part of the exhibition Visual Music: interactions between music and image. This exhibition was held for a period of one month at Brazilian Bank Cultural Center and integrated III Understanding Visual Music Symposium (2015). This international event brought together artists from four continents and has been considered one of the most important academic forums dedicated to the study of the relationship between music and image. The works presented in the exhibition dealt with different possibilities of and the need for interaction with the public. Further, interesting discussions were raised, especially related to the possibilities and need for preservation of these works. These debates were unfolded to the plan of artistic dissemination; moreover, have embraced considerations about ephemeral art.
\end{abstract}

Keywords: visual music, interactive art, ephemeral art, UVM 2015 Symposium

\section{Introduction}

Understanding Visual Music Symposium is an international scientific meeting dedicated to developing and sharing knowledge in a branch of study called visual music. UVM 2015 Symposium focused on research-creation processes and the multiple relations between art, science and new technologies. We understand those are key factors in obtaining creative results when working with a universe composed of moving images and organized sound. During the event, the participants had the opportunity to share research outcomes, experiences, showing their artistic works, as well as to discuss concepts, current trends, technological innovations, aspects related to creativity and innovative use of technology (Corrêa, 2015). UVM 2015 was held in Brasília, Brazil, organized by Midialab_Laboratory of Research in Computer Art. In addition to the 27 visual music pieces screened (selected from more than 100 submissions), the event for the first time incorporated in its program a computer art exhibition. The works presented in this exhibition (entitled Visual Music: Interactions between Music and Image) offered the audience the possibility to participate in the creative elaboration of the work by interacting to the pieces, which were modified due to that interaction. Important artists of the national and international scene were showed, some of them presented in this text. The works dealt with interesting issues such as interactivity and innovative concepts of space-time, and the interfaces between music and image. The relationship between image and music received a special treatment, once most of the works presented in that exhibition explored interactivity possibilities in human-computer interface.

Suzete Venturelli, Ph.D. in Arts, Associated Professor, coordinator of MidiaLab-Laboratory of Research in Computer Art, University of Brasília.

Antenor Ferreira Corrêa, Ph.D. in Music, Associated Professor, coordinator of L-VIS—Laboratory of Postdoctoral Research in Visualization, Representation, and Sonology, University of Brasília. 
As an aesthetic element, interactivity requires presence and contact between the visitor and the work, an aspect that stands as its main feature. The relational poetics of each work with the fields of science and technology is also presented, but in a more subtle way, so intended to soften the bond between those fields. The artists expressed their creativity exploring interfaces that respond to emotions and behaviors of the visitors, which are attracted by the events caused by the work. In this context, visitors are placed in stressful and/or pleasurable situations, so affecting their behavior, which by its turn, provokes sensory reflections. Some of the works represent outcomes of laboratory multimedia research, where the image is inseparable from the sound.

The public interacted naturally with the works, once the designed interfaces responded to visitor movements, leading the audience to feel like a collaborator in the proposed system. However, some works demanded more information about its operation, in order to give the visitors deeper understanding of artist's poetic. In this case, trained guides led the public.

Both in the case of visual music and interactive works displayed, a question came up within the current considerations about the need and feasibility to preserve collections. These discussions eventually also incorporated another contemporary form of artistic expression: ephemeral art. In this sense, what is the real need to preserve a work that only reaches its artistic aim in the presence of the public, which must necessarily interact in order to give life to that work? What is the point in fixing inside a museum a work designed to have a brief existence? These issues unfold to the educational and scientific domain, for bringing the implicit fact that the works must be known by the public to allow themselves to be questioned. To this end, how to improve the dissemination not only of the works but also of the full conceptual apparatus intrinsic to artist's creative poetic?

Following, we analyze the works exhibited at Visual Music: interactions between music and image. First, we presented briefly the references, which accompanied the exhibition of pieces, considering the description offered by their respective creators, which showed their specifics choices and combinations of techniques and technologies. This introduction aims to ground our considerations about interactivity, dissemination and artistic preservation treated throughout the text.

\section{Interactions and Machine-Machine Interfaces With Image and Music}

The artists' desire for the creation of interfaces and interactions between machines, without the presence of other stimuli to occur interactivity, has been experienced more as a function of open sources technologies for the development of hardware as well as software. These two elements are components of computer systems that support the way objects can communicate, as well as the interaction between living things and computers. This type of interaction also considers studies in the field of ubiquitous and pervasive computing (Carro \& Wagner, 2012), meaning that the machine and the software can be everywhere without being noticed. For this, the computer system has to come out of the black boxes, which are industrial computers, to enter the system of computer art, with its own objects and appropriate to the current state of contemporary art. In this context, some works presented in Visual Music exhibition: Interactions Music-image emphasize these aspects.

Paper Garden: Pomegranate and Jewish Slipper Tree (Bergamo, 2015, Figure 1), is composed of two robotic structures based on paper, wire, sensors, actuators and a microcontroller. The structures are planned to exist on a garden composed of other robotic paper structures. All structures are created from an ancestral art system and are evolutionary derivations of it. The objects forms are similar to pomegranate fruit and Jewish tree, and constitute a paper garden permeated by sensors and wires, connected as a vegetable vascular system. 
Figure 1 shows a detail of an object, which produces sounds and lights when in contact with another object of the whole system.

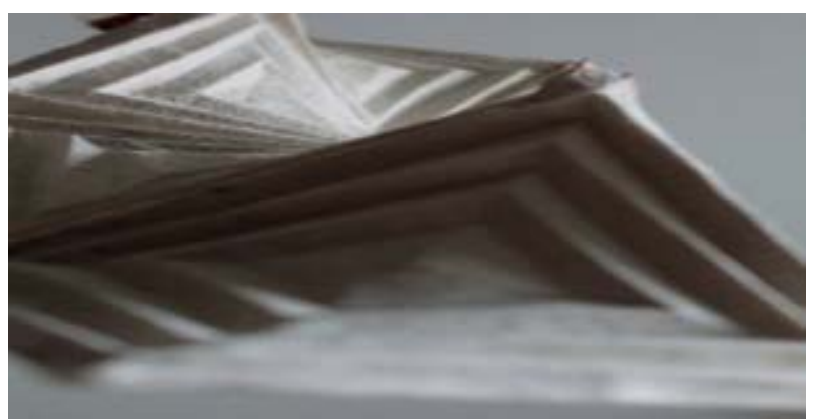

Figure 1. A-Paper Garden: Pomegranate and Jewish Slipper Tree, 2015, Marília Bergamo. Hard paper, wires, sensors and controllers (Copyright by the authors).

This artwork was a learning experience expressed through rhythm, sound, and lights noticeable to the viewer. The visitor and the environment also contribute to the artificial life, another feature of the computer system, which was first established from the communication between two machines.

Sound Analogies (Figure 2) is a sound installation comprised by a mobile that has eight components whose forms were established poetically by the translation of sound into 3D volume. Each of the components of the mobile (represented by the translation of sound into form) has a built-in speaker to reproduce a sound texture that varies continuously. Both, the sound texture and the 3D mobile components, are generated from the same sound material. Therefore, the sound and shape constitute a relationship of mutual interdependence (Tavares, 2015). Combining different media such as picture and sound, authors claim the aesthetic information can be perceived both in form and in sound; therefore, recognizing its poetic meaning.

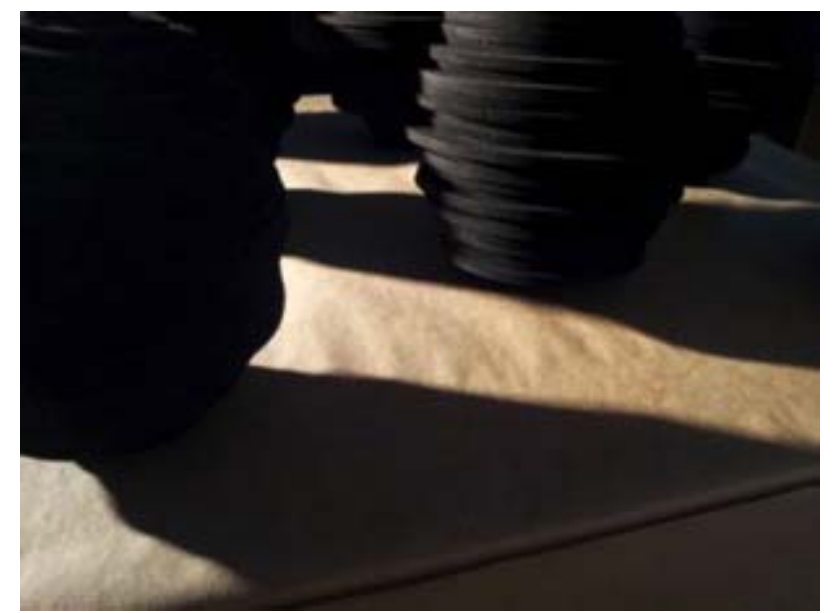

Figure 2. Sound Analogies, 2015, Monica Tavares, Juliana Harrison Henno, and Felipe Merker Castellan. Additive manufacturing, sensors and controllers (Copyright by the authors).

C3 (pronounced C-cubic) is a tangible interface under development by researchers at Media Lab-Federal University of Goiás, for multiuser interaction. The interface consists of three large and illuminated cubes that can be lifted, rotated and moved in a room by a group of people. Each cube detects its orientation (which side has been positioned on the top) and the proximity to the other cubes. For simplicity, the proximity between any pair of cubes was defined only as near (up to two meters) and far (above two meters). This set of three cubes 
allows 63 combinations of upside positioning. Considering only proximity, five different setups are possible (no cube near the others, all three cubes nearby, and three pairwise proximity combinations). In total, the setup offers $63 \times 5=1,080$ combinations. Each one of them can be assigned to a different output involving blinking of lights and sound feedback. The sides of the cubes can be painted with pictures. The interface was thought as a way of transmitting new concepts to the users, for instance, in an educational environment. Motivational activities and pure entertainment are also possible applications for $C 3$. These goals can be reached by assigning the above-mentioned combinations to specific feedbacks. The intensity of the feedbacks can be designed to guide the users to one or more target configurations, in which the images of the three cubes, when visualized together, compose a new concept.

\section{The Body Interface}

Artists seeking for a model of interactivity close to visceral emotional or behavioral consider that the body of the visitors can be the interface itself, once their bodies can automatically respond to events proposed in the works.

Gestus (Figure 3-artwork created especially for this exhibition) presented to visitors the opportunity to experience in real time the creation of sounds and images through gestures of their own hands. A tracker device for computer vision (Leap Motion) recognizes user gestures, registers its spatial position and movements, and sends this information to the virtual environment, so combining them with a pair of virtual hands. The body, by means of the gestures, therefore is the interface that causes undulations in a clustered mesh polygon in three-dimensional virtual environment. As a result, it presents a sort of mesh with ocean swells associated with variations of colors and sounds of piano keys, in dependence of the polygons virtually touched. Gestus (Figure 3 ) is an intuitive and interactive open system, which depends solely on user's gesture (Pratini, 2015). The artwork is also interdisciplinary once it motivates the user to explore a kind of gestural dance.

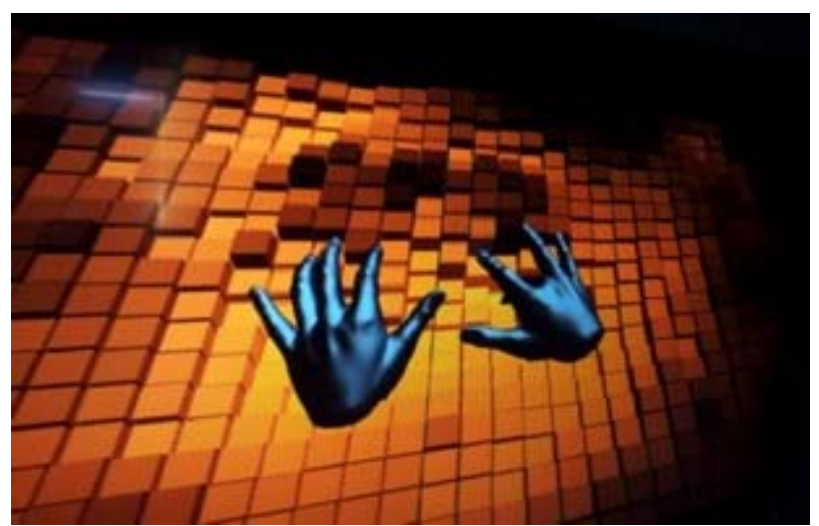

Figure 3. Gestus, 2015, Edison Pratini, Suzete Venturelli, and Tulio Lima. Computer art, sensors and controllers (Copyright by the authors).

\section{Virtual worlds, Game Art, and Interactive Computer Systems}

Expanding the conceptual sense of Visual Music works, the exhibition presented interactive works where sound complemented the narrative in virtual 3D worlds and game art. The game art Snake Chords refers to the popular cellphone game called Snake. However, the player's interaction is quite unusual, because it happens through sound instead cellphone's touch. Snake Chords seeks to provide the players a new playing experience, resizing the idea of a well-known game. To move the snake, it is necessary to play a chord on an instrument, for 
this circumstance, authors choose the guitar. In the game, the virtual Snake obeys the chords E major, E minor, D major and D minor, which turns the interactive experience unusual, either to the musicians or lay people. Close to the artwork, there is a written guide explaining how to make the chords. This chart facilitates the interaction for people who is not acquainted with instrument techniques. Having fun with mistakes and successes is part of its poetic. This game art is more than scoring points because it offers a new way of interaction by a ludic experience of playing the guitar and enchant a snake.

Interactive computer systems require the development of software and hardware to properly address emerging aesthetics issues like the ones directed to reality, experience, and emotions of users. For example, the artwork System/Object: EVA II, experiment I, 2015 (by Daniela Kutschat Hanns, Leandro Velloso, Maurício Galdieri, and André Damião) is a communicative and informational system of environmental events composed of: (a) a generic module for real time capturing and monitoring; (b) custom software modules; (c) an object allowing tangibility of visual, aural and tactile occurrences. The essential topics for the development of an EVA system are: (a) environmental scope: scale and ecosystem specificities; (b) IPO system; (c) the exchange between systems and agents, involving computation, communication and tangibility of sound, light, movement, visual image information, among others. The environmental typology to be monitored and the information gathered (item a) determine the elements of the whole system (items b and c). The occurrences monitored and captured can vary between environmental phenomena, visible or not, larger or smaller scale and scope, for example, seismic events, climate change, light, noise; activities, flows, actions and other interactions between agents and infrastructure.

Ф: An enigma for Gibson 3.1 (by Silvia Laurentiz, Cássia Aranha, Giovanna Lucci, José Dario Vargas, Lali Krotoszynski, Leandro Roman and Loren Bergantini) is part of a set of interactives Enigmas installations, whose audiovisual poetics were inspired by the Flusser, Bergson and Gibson readings. An enigma for Gibson 3.1 executes a real time mapping of light variation within an exhibition room performed by webcams. The information captured is translated respectively in monochromatic lines and synthesized sounds. The synthesized sound varies in frequency, amplitude and stereophonic output according to the information captured by the cameras regarding the quantity of luminous elements. A designed algorithm interprets the information and presents them on screen. The luminous flux, measured in lumens $(\mathrm{lm})$, is responsible for the variations of images and, consequently, of sounds, modifying directly the representations of that space. According to Gibson, these are little variations surrounding allowing for the constitution of perception and rationalized spatial localization.

Decoding reality (by Ricardo Dal Farra) proposes to reflect on what reality is and how everyone can perceive it, understand it and feel it. A visual-music installation that modelling in space mathematically generated images with recorded and imaginary sounds is using contrast as a way to search for linking channels as a possible way to comprehend existence.

What is reality? "A mathematical object” will be answering some philosophers. Is it the one now, or it was yesterday... maybe it will be tomorrow? Is it my own reality, or a collective one? Is it the one of this space, or some other that we cannot penetrate? In Decoding reality, the sounds of life, nature and culture come with images of uncertain worlds, landscapes that we are trying to remember from places where we have not walked yet. Reality is changing, or perhaps each of us is transforming it in a different way. The codes of life seem to avoid permanence. Lonely environments appear, with the resonances of the human that passes. Different and integrated at once, the code to read reality is diluted in the meeting with multiple systems that trespasses life 
experience and remains in time. Is it clear? (invisible maze!) Maybe that is why sometimes we need to look and uneasily find the meaning, decoding the outside and the inside, knowing what is reality. Also this time, yes, to appease fear.

\section{Performances}

The exhibition included the participation of performance artists as Victor Valentine, with his sound visual computing performance Bits in (re) building (Figure 4).

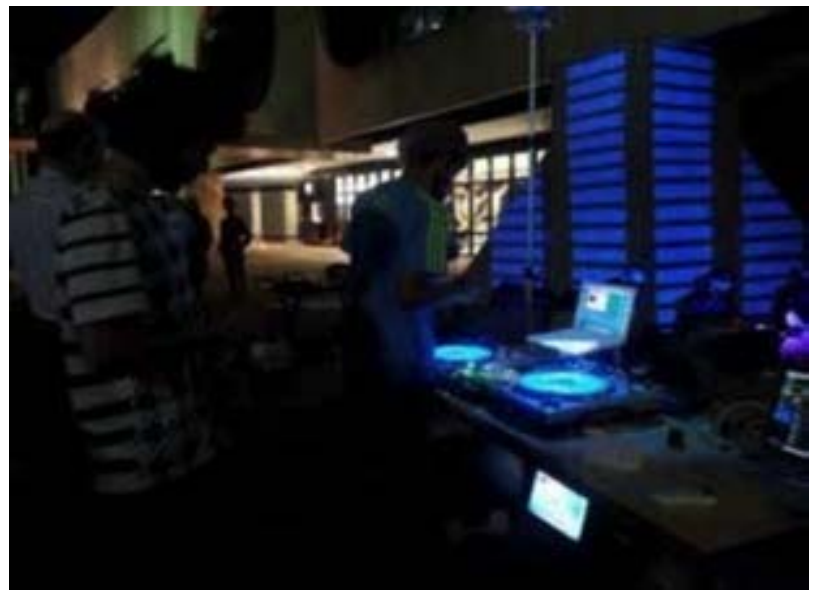

Figure 4. Bits in (re) building, 2015, Victor Valentin. Interactive Performance involving music and lights (Copyright by the authors).

Wilton Azevedo realized the performance De Zen Leio: the virtue of the past (Figure 5). The history of the Health House Francisco Matarazzo, where was the Maternity head office in São Paulo, founded in 1894, closed in 2003, and demolished in 2004, thus ending the historic part of São Paulo architecture. The LHUDI Group has photographed the demolition and, from the pictures, built a generative system used to create the soundtrack and the video of the performance. De Zen Leio is a performative work in real time, which allows the public to create a tension between its personal codes, which degenerate and eventually exclude important landscapes out of memory. The soundtrack leads the images for imagetic degeneration.

The group of Federal University of Rio de Janeiro, conducted the performance Couplings Sensitive, with Janus Cabral and Filipi Dias and Fábio Costa, as a programmer (Figure 6).

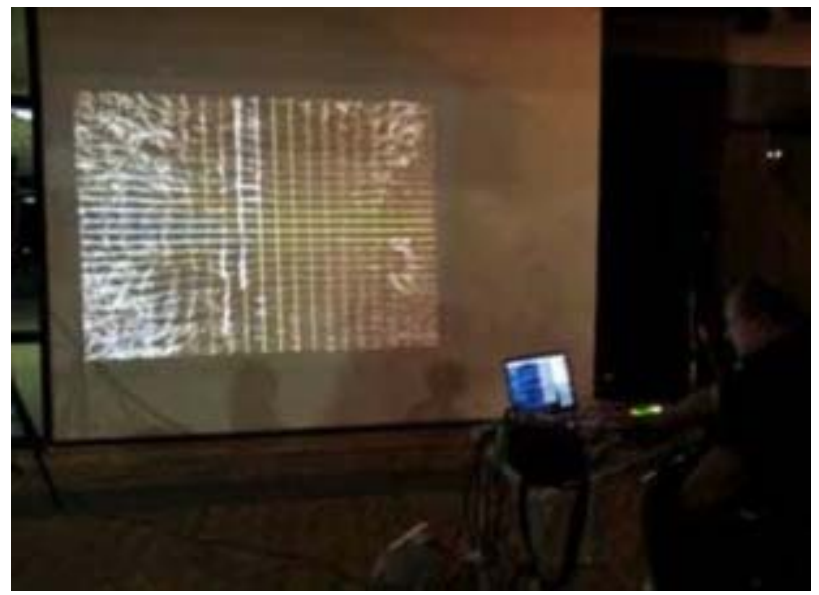

Figure 5. De Zen Leio, 2015, Wilton Azevedo. Performance involving music and images (Copyright by the author). 


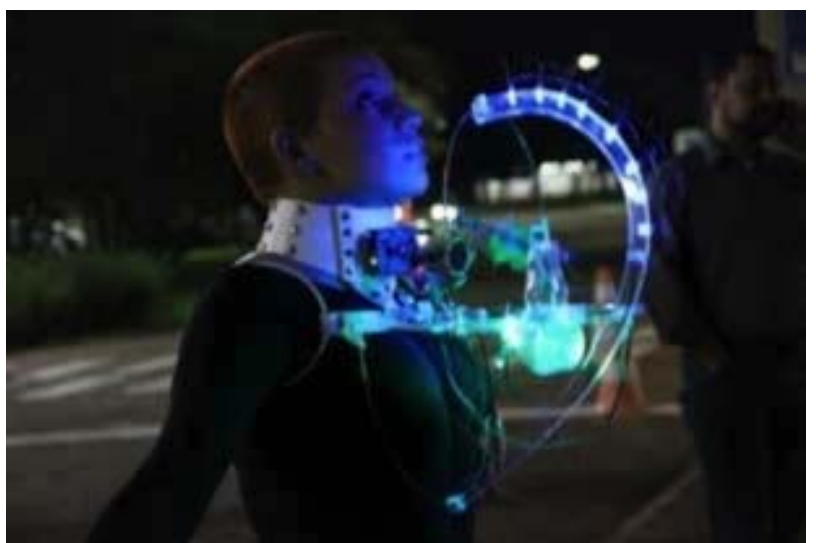

Figure 6. Couplings Sensitive, 2015, coordinators Guto Nobrega and Malu Fragoso. Interactive Performance involving music and lights (Copyright by the authors).

\section{Discussion}

As this summary shows, installations were the main core of Visual Music: Interactions between Music and Image exhibition. Notwithstanding, when thinking of conservation, the first impulse is preserving artistic objects, what have been happening in museums all over the world. However, installations are not artistic objects in a conventional sense of the term. Installations, as well as performances (and perhaps the scope of this discussion can be extended to ephemeral art), are events, and in this sense, one event is something that exists only for the moment it, in fact, happens (for the performances and happenings) or for the period of a particular exhibition (in the case of installations).

Linked with this dichotomy object versus event, we have the issue posited by William Real (2001) claiming that: "while there are conventions within the conservation field for examining, describing, and preserving works of art that exist as objects, there are few such conventions for works of art such as installations that exist for a limited time, are dismantled, and may be re-created at some indeterminate future time and location" (Real, 2001, p. 211). One of the ways generally used to "store" most of nowadays forms of arts is the digital format.

Nevertheless, despite all the promptness and practicalities allowed by digital technologies for storing data, one must take into account the inconvenient they bring attached. As explained by Christoph Black and collaborators (2007), “digital content has a short live span”. The authors claim the astonishing speed changes happening in the field of technology bring as consequence "extreme challenges to the longevity of information". It is not difficult to see the reasons for their concerns. We face several everyday examples of softwares being updated or simply replaced, hardwares becoming obsoletes and disappearing of the market, and so on. Therefore, the files stored in these digital formats can, in a short time, no longer be accessed, causing the loss of that information. It causes the authors argue that "so far, digital objects are inherently ephemeral” (Black et al., 2007).

Within this discussion, we must keep in mind art preservation is not only about the mere storing of artistic artefacts, but it is mainly a form of writing the history of art. Jessica Santone (2008) presents her idea about this matter as follow: "[the artists] seek to contribute to the narrativized and/or mediated understandings of the past that already come after an original moment. Their production of materials is not archival in the sense of creating an ordering or logic to a set or collection, but instead comprises work that repeats and multiplies a historical idea, inflecting its image through a nostalgic lens”. 
Subscribing this idea, we understand all new forms of art, such as digital installations, performances using multi-technological tools, techno happenings, and so on, are part of art history, and denote a critical view of the context they are a part. For that reason, these artworks deserve to be preserved not only with the intention to allow their access in the future, but because they are part of the history of art, and thus manifests understandings and concerns of the zeitgeist they belong in. So to speak, they imply ideals, anxieties, and urgencies, among others, present in the artist's behavior (what is called style) and in the inter-subjective agreements of a group of artists producing at that moment, what is called aesthetic. It might be true, of course, that most of the feelings and sensations promoted by a live performance cannot be stored. How to keep and transfer to the body the emotional contents conveyed during a particular artistic event? How to recreate the experience of being present during a happening? Things like the "weirdness" and "perplexity" caused by the first contact of something unusual are difficult to hold. Even though, if not preserved, how to grant access to future scholars and public interested in knowing more about that particular moment? Moreover, the preservation is the only way to allow other artists re-create or re-perform those artistic events, so causing new oddness and puzzlements.

In reason of that, we understand the need of producing documents regarding these new forms of art, and there are examples good ways to do that. The electronic catalog is one of these ways. With the nowadays enlargement of the capacity for storing data, it is not difficult to create a catalogue containing information given by the artists, as usual, and also recordings of the interactions between public and work, and reactions of the same public to those artworks. Taking advantage of all multimedia technological tools available, it is possible to store a good amount of data about art objects or artistic events itself, as well as public reactions gathered through live recordings during the exhibition and testimonies gathered with participants. Of course, the conceptual drive of the ephemeral and transient esthetics will still be a difficult issue of course; the conceptual foundation of ephemeral and transient esthetics will still be an issue. One can always argue the very nature of transient artwork precludes attempts of preservation. On the other hand, this matter might be approached by discussing directly with the artist, who might or not allow the storing of his/her artwork.

\section{Final Remarks}

From the presented works, some questions can be raised. A performance, for instance, only makes sense at moment it happens, performed by artists and with public involvement. The presence of the viewer in the act of performance is a sine qua non condition for its existence. How to conserve this unique moment? The same could be affirmed about the interactive works, which only become a piece of work, for saying, with the interaction of the viewer. A virtual museum, or even a conventional one (with its usual restrictions and prohibitions regarding public participation), would be the proper way to preserve and disseminate these works?

These concerns turn out to posit another issue that might encompass the idea of ephemeral art, meaning the kind of art that is not made to last, but rather to vanish amidst the power of time. Would not be meaningless the conservation of a type of art that have in its aesthetic root the wish of perishing? On the other hand, in fact, it is possible to justify the maintenance of a physical collection of interactive artworks precisely because of the need for the presence of the public, who gives existence to these works through their interaction.

Several of the artists presented in this paper are also researchers and laboratories coordinator. In those labs, their projects are developed and regarded as artistic research as well. The concepts settled by their works permeate the issues of representation of reality, its simulation, as well as communication between humans and 
machines and between machines only. The life simulation and concerns on our global ecosystem were also present at the exhibition. In this context, the challenge was to externalize provocations caused by Visual Music.

In this sense, the artwork establishes modes for expression of understanding about the world and the relationship with its time. This condition, therefore, constitutes communication between artists and the public. In addition, this communicability should be disseminated to be noticed and subsequently discussed. In addition, the pull towards documentation and preservation should keep into account the originality intended by the artists. In this concern, the Dutch authors IJ sbrand Hummelen and Tatja Scholte made an interesting point by reminding us that:"the production of ephemeral and conceptual works in contemporary art introduces new concepts of transience, which require us to reconsider some of our common preservation strategies for museum collections" (2004).

Although it is not the intention here to provide definitive answers to these questions, we understand that they should be presented and discussed, because they are inquiries offered by the artwork displayed. And, therein lies one of the purposes of art.

\section{References}

Becker, C., Günther, K., Küng, J., \& Rauber, A. (2007). Preserving interactive multimedia art: A case study in preservation planning. 10th International Conference on Asian Digital Libraries, ICADL 2007, Hanoi, Vietnam, December 10-13, Proceedings (pp. 257-266).

Bergamo, M. (2015). A-Paper Garden: Pomegranate and Jewish Slipper tree. Accessed 06/2015. Retrieved from http://youtu.be/bu3jBp0C06c

Carro, L. \& Wagner, F. R. (2012). Desafios para a computação pervasiva no futuro cenário Tecnológico (PPGC-UFRGS).

Correa, A. F. (2015). Proceedings from UVM 2015, accessed 08/2015. Retrieved from http://uvm.unb.br

Hummelen, I., \& Scholte, T. (2004). Sharing knowledge for the conservation of contemporary art: Changing roles in a museum without walls? Journal of the American Institute for Conservation, 49(2), 208-212.

Pratini, E. (2015). Gestus, accessed 08/2015. Retrieved from http://lvis.unb.br

Real, W. A. (2001). Toward guidelines for practice in the preservation and documentation of technology-based installation art. Journal of the American Institute for Conservation, 40(3), 211-231.

Santone, J., \& Abramovic, M. (2008) Seven easy pieces: Critical documentation strategies for preserving art's history. Leonardo, 41(2), 147-152.

Tavares, M. (2015). Sound analogies, accessed 07/2015, Retrieved from: www2.eca.usp.br/nucleos/gp_admd/wp-content/uploads/arte_corpo_tecnologia_vFinal_impressao.pdf. 